\title{
Bactericidal effect of photodynamic therapy against methicillin-resist- ant Staphylococcus aureus strain with the use of various porphyrin photosensitizers
}

\author{
Mariusz Grinholc ${ }^{1 凶}$, Bozena Szramka ${ }^{1}$, Katarzyna Olender ${ }^{2}$ and Alfreda Graczyk ${ }^{2}$ \\ ${ }^{1}$ Department of Biotechnology, Division of Molecular Diagnostics, Intercollegiate Faculty of Biotechnology,

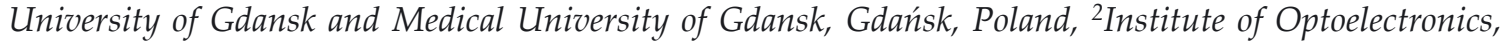 \\ Military University of Technology, Warszawa, Poland
}

Received: 29 May, 2007; revised: 30 July, 2007; accepted: 17 August, 2007

available on-line: 28 August, 2007

\begin{abstract}
Photodynamic therapy (PDT) is based on photosensitizers activated by light of appropriate wavelength. Their activation leads to generation of singlet oxygen and free radicals responsible for the cytotoxic effect. The aim of this project was to compare the bactericidal effect of PDT using different porphyrin photosensitizers against a methicillin-resistant Staphylococcus aureus strain. Exogenous sensitizers (protoporphyrin IX and newly synthesized derivative, protoporphyrin diarginate) induced a $3 \log _{10}$-unit reduction in bacterial viable counts. With the use of endogenous, ALA-induced porphyrins, a $1.6 \log _{10}$-unit reduction was obtained. The sensitizers tested executed their antibacterial activity with no essential change in the antibiotic resistance pattern of the studied strain.
\end{abstract}

Keywords: MRSA, photodynamic therapy, photosensitizer, porphyrin

\section{INTRODUCTION}

Photodynamic therapy (PDT) is a potential therapy against cancerous tumours (Szurko et al., 2003; Chwilkowska et al., 2003) and has recently been studied against a wide range of bacteria, fungi, yeasts, and viruses that cause serious problems of contemporary medicine (Jori \& Brown, 2004). Photodynamic therapy is based on chemicals called photosensitizers that are activated by light of adequate wavelength. Its activation leads to the generation of singlet oxygen and free radicals responsible for the cytotoxic effect against specific cells (Romanova et al., 2003). The aim of this study was to analyze the bactericidal effect of PDT against methicillin-resistant Staphylococcus aureus (MRSA) which is the most important etiological agent responsible for hospital-acquired infections (Kurlenda et al., 2007). Some
MRSA infections may be life-threatening, especially in the case of immuno-compromised patients, causing bacteremia, endocarditis, sepsis or toxic-shock syndrome (Jarraud et al., 2002). Their multiresistance to antibiotics leads to many therapeutic problems, and for this reason an alternative method to antibiotic therapy needs to be developed. It seems that photodynamic therapy may be an effective and alternative therapeutic option against $S$. aureus strains (Embleton et al., 2004; Gad et al., 2004) and potentially against other bacterial pathogens like S. epidermidis (Zeina et al., 2001; Gad et al., 2004), Propionibacterium acnes (Ashkenazi et al., 2003) Listeria monocytogenes (Romanova et al., 2003), Streptococcus pyogenes, Corynebacterium minutissimum, Bacillus subtilis, and Enterococcus faecalis (Shawar \& Cooper, 1990; Zeina et al., 2001). Different chemical compounds with photoactive properties have already

Corresponding author: Mariusz Grinholc, Department of Biotechnology, Division of Molecular Diagnostics, Intercollegiate Faculty of Biotechnology, University of Gdansk and Medical University of Gdansk, Kładki 24, 80-822 Gdańsk, Poland; tel./fax: (48 58) 301 2807; e-mail: grinholc@biotech.ug.gda.pl

Abbreviations: ALA, $\delta$-aminolevulinic acid; c.f.u., colony forming units; MRSA, methicillin-resistant Staphylococcus aureus; PDT, photodynamic therapy; PPArg ${ }_{2}$, protoporphyrin diarginate; PPIX, protoporphyrin IX. 
been tested against Gram-positive bacteria. Various photosensitizers such as haematoporphyrin (Bertoloni et al., 2000), porphyrin derivatives (Lasocki et al., 1999; Lambrechts et al., 2005), phenothiazinium salts (Bisland et al., 2006; Tegos \& Hamblin, 2006), chlorin (i.e. SnCe6) (Gad et al., 2004; Embleton et al., 2005) and $\delta$-aminolevulinic acid-induced porphyrin sensitizers (Nitzan et al., 2004; Bisland et al., 2006) were studied and found to demonstrate a high bactericidal effect after illumination with visible light against S. aureus strains.

Photoactivated sensitizers such as protoporphyrin IX (PPIX) and arginine haematoporphyrin derivatives $\left(\mathrm{HpD}-\mathrm{Arg}_{2}\right)$ reveal bactericidal activity against several bacterial species, including MRSA (Orenstein et al., 1997; Lasocki et al., 1999). Protoporphyrin diarginate $\left(\mathrm{PPArg}_{2}\right)$, which was recently synthesized and has not been described yet, was used in this study. Additionally, previously published studies demonstrate that $S$. aureus is able to produce high amounts of porphyrins upon induction by $\delta$ aminolevulinic acid (ALA) which may be used as an ideal stimulator of endogenous sensitizer production in photodynamic therapy (Nitzan et al., 2004; Bisland et al., 2006). The aim of this study was to compare the bactericidal effect achieved by the action of the above-mentioned photosensitizers.

As damage of genomic and plasmid DNA is one of the results of photodynamic activity (Romanova et al., 2003) and some antibiotic resistance mechanisms are DNA-dependent, a change in the resistance pattern has been suggested to be observed. The influence of photodynamic therapy on the antibiotic resistance pattern of the studied strain was therefore analyzed.

\section{MATERIALS AND METHODS}

Protoporphyrin diarginate. PPArg 2 is a newly synthesized chemical compound and its bactericidal effect as a photosensitizer has not been studied so far. Its synthesis, purification and molecular characterization is described in published Polish, European and United States patents (Konarski, 1990; PadzikGraczyk et al., 1993; Graczyk \& Konarski, 1994; 1995; Graczyk \& Konarski, 1997). The molecular data concerning PPArg ${ }_{2}$, such as molecular formula, molecular weight, composition and nominal mass are presented in Fig. 1. The molecular data concerning unmodified protoporphyrin IX are presented in Fig. 2.

MRSA isolate. The investigated clinical strain of MRSA (methicillin-resistant Staphylococcus aureus), of known resistance level (Table 1), was isolated from the Provincial Hospital in Gdańsk. The isolate was characterized by Gram-staining and its ability to produce coagulase and clumping factor using Slidex Staph Plus (BioMerieux). Additionally, the species was identified using the biochemical identification system ID 32 Staph (BioMerieux).

Photodynamic therapy. Photodynamic therapy with the use of exogenous porphyrin photosensitizers was conducted as follows: stock solutions of photosensitizers at a concentration of $10 \mathrm{mM}$ were prepared (PPIX (MP Biomedicals) in 100\% DMSO (Sigma) and PPArg 2 in distilled water) and stored at $-20^{\circ} \mathrm{C}$ in the darkness until use. The bacterial culture was grown overnight at $37^{\circ} \mathrm{C}$ in nutrient trypcase soy broth (BioMerieux) and then diluted with fresh broth to the density $\mathrm{OD}_{600} 0.05$. An appropriate volume of stock photosensitizer solution (0.8 to $4 \mu \mathrm{l})$ was added to $0.8 \mathrm{ml}$ of the MRSA culture to achieve the desired final concentration, from 10 to 50 $\mu \mathrm{M}$. The culture was incubated at $37^{\circ} \mathrm{C}$ for $15 \mathrm{~min}$ in the darkness and then loaded into a 96-well plate and treated with an appropriate light dose. The total volume of the culture in each well was $0.1 \mathrm{ml}$. An identical microplate was incubated in the darkness in the same conditions and served as a control. Thus, there were three types of controls: S. aureus treated solely with light, kept with photosensitizer in the darkness and S. aureus kept without sensitiz-

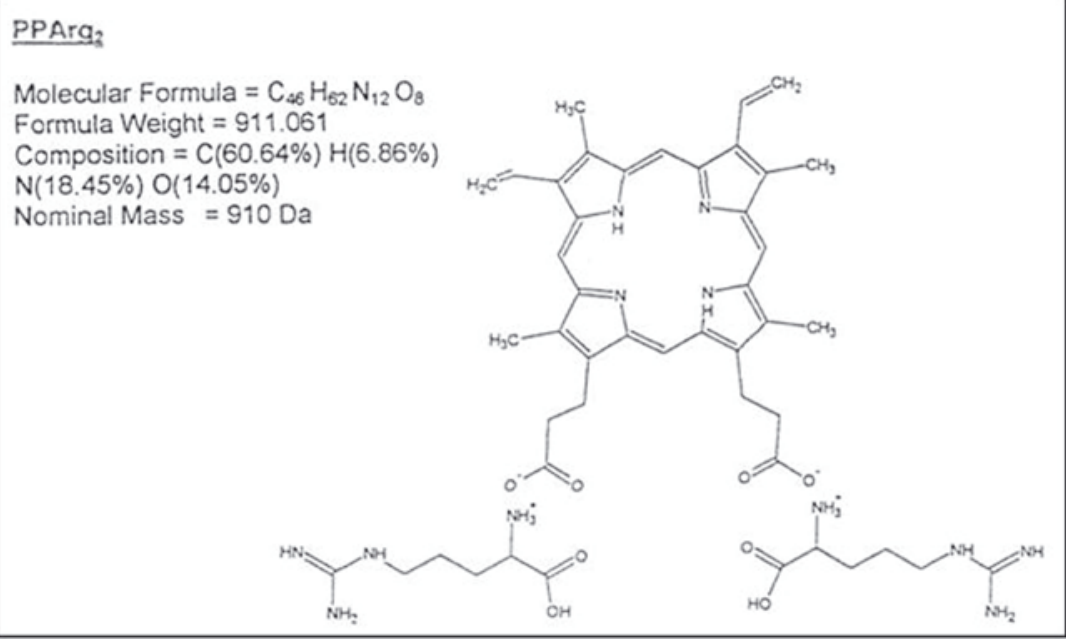

PPArg $_{2}$

Molecular Formula $=\mathrm{C}_{46} \mathrm{H}_{62} \mathrm{~N}_{12} \mathrm{O}_{8}$ Formula Weight $=911.061$ $\mathrm{N}(18.45 \%) \mathrm{O}(14.05 \%)$ Nominal Mass $=910 \mathrm{Da}$

Figure 1. Molecular characteristics of protoporphyrin diarginate (PPArg 2 ). 


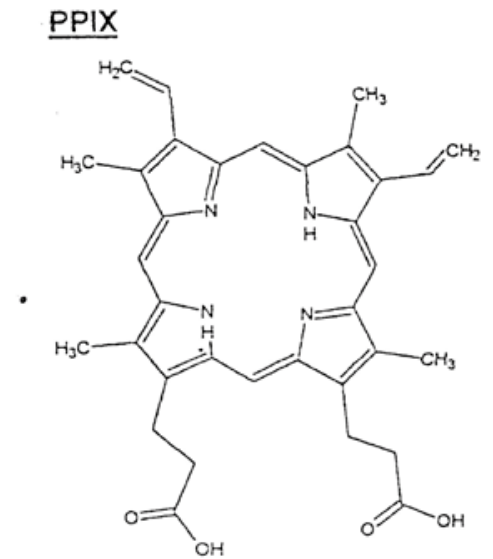

er and light. After the illumination, aliquots $(10 \mu \mathrm{l})$ were taken from each well to determine the number of colony-forming units (c.f.u.). The aliquots were serially diluted 10 -fold in PBS $(0.13 \mathrm{~mol} / \mathrm{l} \mathrm{NaCl}, 8.1$ $\mathrm{mmol} / 1 \mathrm{Na}_{2} \mathrm{HPO}_{4}, 1.47 \mathrm{mmol} / 1 \mathrm{KH}_{2} \mathrm{PO}_{4}, 2.68 \mathrm{mmol} /$ $1 \mathrm{KCl}$ ) to give dilutions of $10^{-3}$ (for PDT with PPIX and $\mathrm{PPArg}_{2}$ ) and $10^{-4}$ (for PDT with ALA). Aliquots $(10 \mu \mathrm{l})$ of each of the dilutions were plated on trypcase soy agar (BioMerieux). After $18 \mathrm{~h}$ of incubation at $37^{\circ} \mathrm{C}$ in the darkness the colonies formed were counted and the results were analyzed statistically. In the case of ALA-induced production of endogenous porphyrins analogous conditions were used, with the $\delta$-aminolevulinic (MP Biomedicals) stock concentration of $1 \mathrm{M}$ prepared in distilled water and the time of incubation of the bacterial culture with ALA ranging from 1 to 24 hours. The final concentration of ALA was $10 \mathrm{mM}$. Each experiment was done three times.

Antibiotic susceptibility. The antibiotic susceptibility of PDT-treated and untreated strain was determined by the disc-diffusion method according to the criteria of the recommendations for susceptibility testing (Hryniewicz et al., 2005). The influence of the PDT treatment on the antibiotic susceptibility was tested under experimental conditions showing the highest level of the bactericidal effect. In the case of exogenous sensitizers, it was done at the concentration of $50 \mu \mathrm{M}$ and the light dose of $12 \mathrm{~J} / \mathrm{cm}^{2}$. When the endogenous sensitizers were analyzed, the antibiotic susceptibility was determined after the PDT treatment following $24 \mathrm{~h}$ incubation with ALA and the light dose of $50 \mathrm{~J} / \mathrm{cm}^{2}$. After the PDT treatment, 10- $\mu \mathrm{l}$ aliquots of each of the dilutions were plated as above, incubated for $18 \mathrm{~h}$ at $37^{\circ} \mathrm{C}$ in the darkness, then five colonies were picked at random, diluted in PBS and used to determine the antibiotic susceptibility (Hryniewicz et al., 2005). The following antibiotic discs were used: oxacillin (OX, $1 \mu \mathrm{g})$, erythromycin $(\mathrm{E}, 15 \mu \mathrm{g})$, lincomycin $(\mathrm{L}, 15 \mu \mathrm{g})$, gentamycin $(\mathrm{GM}, 10 \mu \mathrm{g})$, ciprofloxacin (CIP, $5 \mu \mathrm{g})$, sulpha-
Figure 2. Molecular characteristics of protoporphyrin IX (PPIX).

methoxazole/Trimethoprim (SXT, 23.75/1.25 $\mu \mathrm{g}$ ) and vancomycin (VA, $30 \mu \mathrm{g}$ ) for a standard antibiogram, and tetracycline (TE, $30 \mu \mathrm{g})$, rifampicin (RA, $5 \mu \mathrm{g}$ ), fusidic acid (FA, $10 \mu \mathrm{g})$, penicillin $\mathrm{G}$ (PEN, 10 units), ampicillin (AMP, $10 \mu \mathrm{g}$ ), mupirocin (MUP, $200 \mu \mathrm{g}$ ), nitrofurantoin (NF, $300 \mu \mathrm{g})$, ofloxacin (OFX, $5 \mu \mathrm{g}$ ), trimethoprim (TMP, $5 \mu \mathrm{g}$ ), teicoplanin (TEC, $30 \mu \mathrm{g}$ ), chloramphenicol (CHL, $30 \mu \mathrm{g})$, clindamycin (DA, $2 \mu \mathrm{g}$ ), netilmicin (NET, $30 \mu \mathrm{g}$ ), tobramycin (TOB, $10 \mu \mathrm{g})$, amikacin (AK, $30 \mu \mathrm{g})$, kanamycin $(\mathrm{K}, 30 \mu \mathrm{g})$, linezolid (LZD, $30 \mu \mathrm{g}$ ), telithromycin (TEL, $15 \mu \mathrm{g}$ ) and quinupristin/dalfopristin (QD, $15 \mu \mathrm{g}$ ) for an extended antibiogram.

Light source. The illumination was carried out using a BioStimul Lamp which emits polarized (96\% level of polarization) monochromatic light (624 $\mathrm{nm} \pm 18 \mathrm{~nm}$ ) (BIOTHERAPY, Czech Republic). A light power meter (model LM1, CARL ZEISS, Jena, Germany) served to determine the delivered light energy, which was approx. $0.2 \mathrm{~J} / \mathrm{cm}^{2}$ per minute.

\section{RESULTS AND DISCUSSION}

Protoporphyrin IX as well as $\operatorname{PPArg}_{2}$ exert an effective antibacterial activity even in the concentration of $10 \mu \mathrm{M}$, illumination lasting for $60 \mathrm{~min}$ and the light dose of only $12 \mathrm{~J} / \mathrm{cm}^{2}$. In these experimental conditions the phototoxic effect resulted in 2.4 and $2.1 \log _{10}$-unit reduction in viable counts (for PPIX and $\mathrm{PPArg}_{2}$, respectively). A cytotoxic effect of 0.2 and $0.22 \log _{10}$-unit reduction was observed (for PDT with PPIX and PPArg ${ }_{2}$, respectively) (Figs. 3 and 4). As DMSO was used to dissolve the non-polar PPIX, the cytotoxicity of DMSO as a control solution was analyzed. To give the final concentration of PPIX ranging from 10 to $50 \mu \mathrm{M}$, the concentrations of DMSO were 0.1 to $0.5 \%$, respectively. No cytotoxic or phototoxic effect of DMSO was observed at these conditions (not shown). When the ALA-induced endogenous porphyrins were studied, the bactericidal 


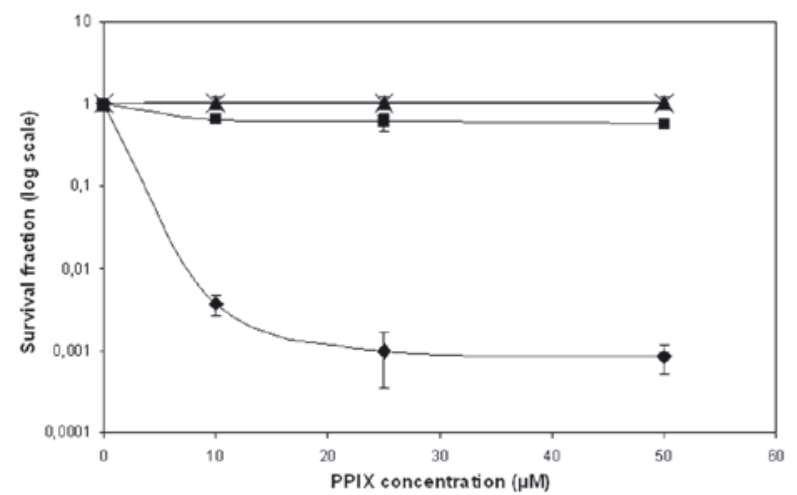

Figure 3. Photo- and cytotoxic effect of protoporphyrin IX (PPIX) with the light dose of $12 \mathrm{~J} / \mathrm{cm}^{2}$.

The survival rate was calculated from the number of c.f.u. in the PDT-treated sample divided by the number of c.f.u. in the sample kept in the darkness without photosensitizer. Designations are as follows: PDT-treated S. aureus ( $\bullet)$, $S$. aureus treated solely with light $(\mathbf{\Lambda})$, kept with photosensitizer in the darkness (घ), and without sensitizer and light $(\mathbf{x})$. Each experiment was done three times, and error bars show S.D.

effect of $1.6 \log _{10}$-unit reduction was obtained after $24 \mathrm{~h}$ of incubation and the light dose of $50 \mathrm{~J} / \mathrm{cm}^{2}$ (Fig. 5). The cytotoxic effect after this incubation time was approx. $0.3 \log _{10}$-unit reduction.

Lasocki et al. (1999) reported that photodynamic therapy with the use of another water-soluble porphyrin sensitizer, haematoporphyrin diarginate derivative $\left(\mathrm{HpD}-\mathrm{Arg}_{2}\right)$, at the concentration of $25 \mu \mathrm{g} / \mathrm{ml}$ revealed a high bactericidal effect against S. aureus. In their studies $99.99 \%$ eradication was reached with the illumination carried out using a home-made visible light source (the light intensity was $80 \mathrm{klx}$ and the illumination time was $30 \mathrm{~min}$ ). Similar results were obtained by Szpakowska et al. (2001). In those studies, regarding MRSA strains, the minimal bactericidal concentration $(\mathrm{MBC})$ of $\mathrm{HpD}$ -

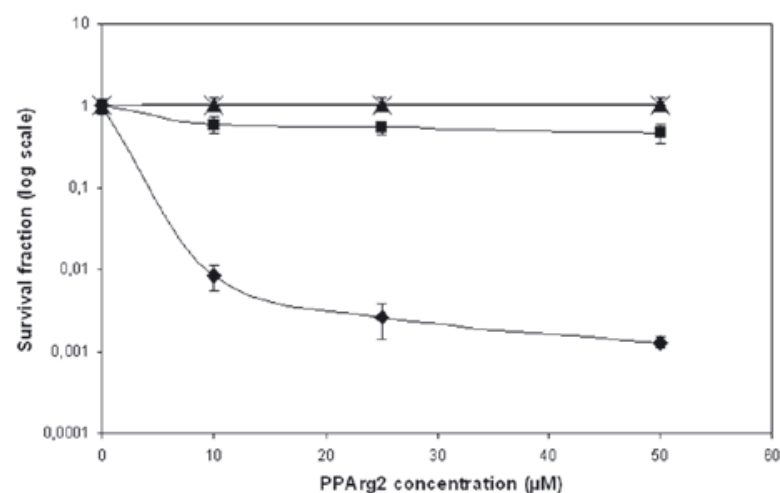

Figure 4. Photo- and cytotoxic effect of $\mathrm{PPArg}_{2}$ with a light dose of $12 \mathrm{~J} / \mathrm{cm}^{2}$.

Survival fraction determined as in Fig. 3. Designations are the same as in Fig. 3.

$\mathrm{Arg}_{2}$ ranged from 1.6 to $50 \mu \mathrm{g} / \mathrm{ml}$. Our studies show that concentration of $9 \mu \mathrm{g} / \mathrm{ml}$ of protoporphyrin diarginate gives a $(99.4 \%) 2.2 \log _{10}$-unit reduction in viable counts. A $(99.9 \%) 3 \log _{10}$-unit reduction was achieved using the concentration of $45 \mu \mathrm{g} / \mathrm{ml}$ (50 $\mu \mathrm{M})$ of PPArg 2 . However, in our studies the illumination of the bacterial cultures was performed with the use of a $630 \mathrm{~nm}$ wavelength light source. Banfi et al. (2006) studied the antibacterial activity of different tetraaryl-porphyrin photosensitizers and showed that even in the concentration of $1-3 \mu \mathrm{M}$ an almost $7 \log _{10}$-unit decrease could be obtained. However, their studies were performed with the use of broadband white light $(380-780 \mathrm{~nm}$ ) of a $500 \mathrm{~W}$ tungstenhalogen lamp and the delivered light energy was approx. $133 \mathrm{~J} / \mathrm{cm}^{2}$. In our studies the delivered light energy was only $12 \mathrm{~J} / \mathrm{cm}^{2}$. Porphyrin-based photosensitizers were also studied by Maisch et al. (2005). In their studies incubation with only $0.005 \mu \mathrm{M}$ porphyrin-derivative sensitizer followed by illumination yielded a $3 \log _{10}$-decrease in the viable cells. We

Table 1. Antibiotic susceptibility of PDT-treated and untreated S. aureus strain.

\begin{tabular}{|c|c|c|c|c|c|c|c|c|c|c|}
\hline \multirow[t]{3}{*}{ S. aureus } & \multicolumn{10}{|c|}{ Antibiotics ${ }^{\mathrm{a}}$ : } \\
\hline & \multicolumn{10}{|c|}{ Standard antibiogram } \\
\hline & OX & $E$ & L & GM & CIP & SXT & VA & & & \\
\hline Untreated & 0 & 0 & 18 & 0 & 0 & 27 & 20 & & & \\
\hline \multirow[t]{3}{*}{ PDT-treated ${ }^{b}$} & 0 & 0 & 17 & 0 & 0 & 26 & 19 & & & \\
\hline & \multicolumn{10}{|c|}{ Extended antibiogram } \\
\hline & TE & RA & FA & PEN & AMP & MUP & NF & OFX & TMP & TEC \\
\hline Untreated & 10 & 32 & 36 & 10 & 14 & 38 & 30 & 15 & 35 & 21 \\
\hline \multirow[t]{2}{*}{ PDT-treated ${ }^{b}$} & 10 & 30 & 34 & 10 & 13 & 36 & 30 & 14 & 33 & 20 \\
\hline & CHL & DA & NET & ТОВ & AK & K & LZD & TEL & QD & \\
\hline Untreated & 34 & 28 & 35 & 36 & 33 & 32 & 30 & 21 & 25 & \\
\hline PDT-treated ${ }^{\mathrm{b}}$ & 34 & 26 & 34 & 34 & 32 & 32 & 30 & 20 & 25 & \\
\hline
\end{tabular}

${ }^{a}$ For abbreviations used see Materials and Methods in Antibiotic susceptibility paragraph. ${ }^{\mathrm{b} P \mathrm{Arg}} \mathrm{A}_{2} \mathrm{based}$ photodynamic therapy (sensitizer concentration $50 \mu \mathrm{M}$ and the light dose of $12 \mathrm{~J} / \mathrm{cm}^{2}$ ). The resistance pattern was determined with the disc-diffusion method (numbers present the diameters of zones of growth inhibition in $\mathrm{mm}$ ). 


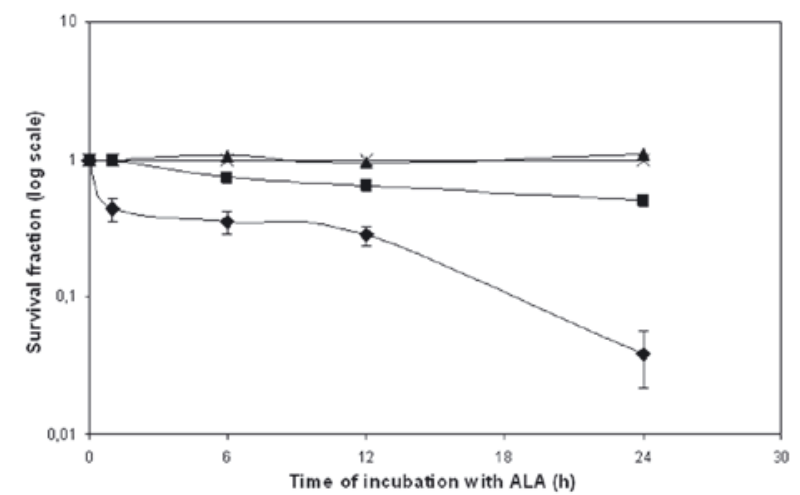

Figure 5. Photo- and cytotoxic effect of $10 \mathrm{mM}$ ALA with a light dose of $50 \mathrm{~J} / \mathrm{cm}^{2}$.

Survival fraction determined as in Fig. 3. Designations are the same as in Fig. 3.

suppose that such a high bactericidal effect resulted from the illumination performed with an incoherent light source with the emission $\lambda$ of 380 to $480 \mathrm{~nm}$. It must be considered that the absorption spectra of porphyrins show an intense Soret band with a maximum centered at about $422 \mathrm{~nm}$ and a series of weak bands, between 500 and $650 \mathrm{~nm}$, whose intensities are below $5 \%$ of the Soret band intensity. Thus, illumination carried out with a 380-480 nm light source results in a much more efficient excitation of the porphyrin sensitizers.

In the case of ALA-induced production of endogenous porphyrin sensitizers, Nitzan et al. (2004) reported that staphylococcal strains produced high amounts of porphyrins when incubated with 0.38 mM ALA for $4 \mathrm{~h}$. Upon illumination of the ALA-induced strains with $407-420 \mathrm{~nm}$ blue light, a decrease of five orders of magnitude was demonstrated with a light dose of $50 \mathrm{~J} / \mathrm{cm}^{2}$. Total eradication could be achieved with a $100 \mathrm{~J} / \mathrm{cm}^{2}$ dose. In our studies a $1.6 \log _{10}$-unit reduction in viable counts was reached after $24 \mathrm{~h}$ of incubation with $10 \mathrm{mM}$ ALA and the light dose of $50 \mathrm{~J} / \mathrm{cm}^{2}$. Probably, such ambiguous bactericidal effects result from illumination performed with the use of a different light source. Although $\delta$-aminolevulinic acid is known to be phototoxic, it was important to evaluate its bactericidal effect using the same experimental conditions as for PPArg $_{2}$ and PPIX. This allowed the conclusion to be drawn that exogenous sensitizers exert a higher bactericidal effect than the endogenous sensitizers produced upon administration of ALA. When the light dose of $12 \mathrm{~J} / \mathrm{cm}^{2}$ was delivered to the studied sample, no bactericidal effect could be observed (not shown). Moreover, the 24-hour incubation with ALA is not suitable as a treatment scheme from the clinical point of view. This incubation time could probably be shortened even to $4 \mathrm{~h}$ according to Nitzan et al. (2004) when a light source emitting 407-420 nm blue light is used.

On the basis of these preliminary studies we may conclude that all the photosensitizers tested, including ALA-induced endogenous porphyrins, may exert a high bactericidal effect against methicillin-resistant S. aureus strains. Moreover, protoporphyrin diarginate $\left(\mathrm{PPArg}_{2}\right)$ was as effective as unmodified protoporphyrin IX. Being water-soluble, PPArg may penetrate the infected tissues deeper and hence exert its bactericidal effect more effectively, which is significant from the clinical point of view. Moreover, the fact that PPArg ${ }_{2}$ is water-soluble eliminates the use of DMSO or other cytotoxic solvent to prepare the solution of the photosensitizer. This is clinically important, as such toxic compounds may decrease the viability of eukaryotic cells surrounding the site of bacterial infection. The obtained results suggest that protoporphyrin diarginate may exert a high antibacterial effect. However, more efficient, although also more complicated, photoinactivation systems have been found, i.e. those described by Embleton et al. (2005) using phage-mediated delivery of the sensitizer into the target cell. Another effective photoinactivation system for methicillin-resistant $S$. aureus strains is proposed by Ferro et al. (2006) who suggest the use of liposome-mediated delivery of the photosensitizing agents.

Additionally, we asked whether the resistance pattern of the studied MRSA strain changes in the course of PDT action using both endogenous and exogenous sensitizers. Malik et al. (1994) revealed that bacteria surviving porphyrin treatment had an impaired resistance to penicillin caused by the damage of plasmids responsible for 13-lactamases synthesis. In our study no essential change in the resistance pattern was observed. The resistance to antibiotics was the same before and after the PDT treatment based on exogenous as well as endogenous photosensitizers. The obtained results suggest that photodynamic therapy with the use of protoporphyrin diarginate may be an effective bactericidal method against multiresistant Staphylococcus aureus strains and potentially against other bacterial pathogens.

\section{Acknowledgements}

This work was supported by the University of Gdansk, grant number B 051-5-0042-5 and the European Social Fund and Polish Government under project no. Z/2.22/II/2.6/002/05.

We are grateful to Natalia Jarzebska for critical reading of the manuscript. The technical assistance of Krystyna Bogucka from the Department of Bacteriology (Provincial Hospital in Gdańsk) is gratefully acknowledged. 


\section{REFERENCES}

Ashkenazi H, Malik Z, Harth Y, Nitzan Y (2003) FEMS Immunol Med Microbiol 35: 17-24.

Banfi S, Caruso E, Buccafurni L, Battini V, Zazzaron S, Barbieri P et al. (2006) J Photochem Photobiol B 85: 28-38.

Bertoloni G, Lauro FM, Cortella G, Merchat M (2000) Biochim Biophys Acta 1475: 169-174.

Bisland SK, Chien C, Wilson BC, Burch S (2006) Photochem Photobiol Sci 5: 31-38.

Chwilkowska A, Saczko J, Modrzycka T, Marcinkowska A, Malarska A, Bielewicz J, Patalas D, Banas T (2003) Acta Biochim Polon 50: 509-513.

Embleton ML, Nair SP, Cookson BD, Wilson M (2004) Microb Drug Resist 10: 92-97.

Embleton ML, Nair SP, Heywood W, Menon DC, Cookson BD, Wilson M (2005) Antimicrob Agents Chemother 49: 3690-3696.

Ferro S, Ricchelli F, Mancini G, Tognon G, Jori G (2006) J Photochem Photobiol B 83: 98-104.

Gad F, Zahra T, Hasan T, Hamblin MR (2004) Antimicrob Agents Chemother 48: 2173-2178.

Graczyk A, Konarski J (1994) Polish Patent, PL 165 249, B1.

Graczyk A, Konarski J (1995) United States Patent 5451 599.

Graczyk A, Konarski J (1997) European Patent Specification EPO 539960 B1.

Hryniewicz W, Sulikowska A, Szczypa K, Gniadkowski M, Skoczyńska A (2005) Adv Microbiol 44: 175-192.

Jarraud S, Mougel Ch, Thioulouse J, Lina G, Meugnier H, Forey $\mathrm{F}$ et al. (2002) Infect Immun 70: 631-641.

Jori G, Brown SB (2004) Photochem Photobiol Sci 3: 403-405.
Konarski J (1990) CL5CO7D487122 no. 148775.

Kurlenda J, Grinholc M, Jasek K, Wegrzyn G (2007) Med Sci Monit 13: MT13-18.

Lambrechts SAG, Demidova TN, Aalders MCG, Hasan T, Hamblin MR (2005) Photochem Photobiol Sci 4: 503-509.

Lasocki K, Szpakowska M, Grzybkowski J, Graczyk A (1999) Pharmacol Res 39: 181-184.

Maisch T, Bosl C, Szeimies RM, Lehn N, Abels C (2005) Antimicrob Agents Chemother 49: 1542-1552.

Malik Z, Ladan H, Nitzan Y, Smetana Z (1994) Photodynamic Therapy of Cancers (Jori G, Moan J, Star W.M. eds) Proc SPIE 2078: 305-312.

Nitzan Y, Salmon-Divon M, Shporen E, Malik Z (2004) Photochem Photobiol Sci 3: 430-435.

Orenstein A, Klein D, Kopolovic J, Winkler E, Malik Z, Keller N et al. (1997) FEMS Immunol Med Microbiol 19: 307-314.

Padzik-Graczyk A, Konarski J, Sobczynska J (1993) Polish Patent, PL 165 248, B1.

Romanova NA, Brovko LY, Moore L, Pometun E, Savitsky AP, Ugarova NN et al. (2003) Appl Environ Microbiol 69: 6393-6398.

Shawar R, Cooper BH (1990) Photochem Photobiol 52: 825830.

Szpakowska M, Lasocki K, Grzybowski J, Graczyk A (2001) Pharmacol Res 44: 243-247.

Szurko A, Krämer-Marek G, Wide M, Ratuszna A, Habdas J, Kus P (2003) Acta Biochim Polon 50: 1165-1174.

Tegos GP, Hamblin MR (2006) Antimirob Agents Chemother 50: 196-203.

Zeina B, Greenman J, Purcell WM, Das B (2001) Br J Dermatol 144: 274-278. 